\title{
How disease looks at us
}

\author{
Martin Riegler
}

Published online: 19 February 2020

(C) Springer-Verlag GmbH Austria, part of Springer Nature 2020

\section{Dear reader,}

Welcome to this issue of European Surgery. Thanks for taking your time to read those lines. You are an exception. Did you know that before? Do you harbour a strong or a weak personality? Modern life does not provide much time for source reading against group think. Did you get the full meaning of the sentence? If not, do not mind to read it again and again. Why? You also tend to become a victim of google god manipulated reasoning, perception and understanding. It is much easier to be a group thinker. Instead it is much harder to develop individual reasoning, to evaluate opinions (Sir Prof Dr Karl Popper!). Thanks for being open to swallow these lines. A swallow also indicates a distinct, special bird. May the swallow swallow its own wings? May that beautifully describe our current situation, the real situation? Let us fly!

This issue of European Surgery orchestrates a broad spectrum of themes, motives and topics of academical surgery including minimally invasive, liver, endocrine, colorectal and hernia surgery. We have to thank the authors, the reviewers and the publisher to make the project possible. Why is European Surgery different? What makes European Surgery different, when compared to other publications in the field, in the wave, in the quantum based academical conduct of reasoning? European Surgery aims to serve those people (you?), who wish to address the most striking, most important and most valuable scope, focus and topic of our life, of your life, dear reader: going in line with the recent issues, European Surgery aims to approximate the world myth of man, as assessed under the perspec-

Doz. Dr. M. Riegler $(\bowtie)$

Reflux \& Health Care, Mariannengasse 10/4/9, 1090 Vienna, Austria

martin.riegler@refluxordination.at tive of human reasoning and perception. Any human activity, even your daily surgery, is part of the world myth of man. As thus we open our pages and ask: "What is now?" Would you allow to give an answer? If you think, that your life does not allow to follow those lines, because you think, that those lines do not harbour actuality, novelty and relevance, then you may skip those pages and return (reflux) later or never (no reflux!). Irrespective of your decision: life goes on, being goes on and does not matter if you care about those topics or not. It happens, even, when you are not aware of it.

In the recent issues of European Surgery we found that surgery (diagnosis, therapy) operates using the fundamental qualities of myth. As thus, using the codes of medicine, surgery translates images into treatable signs. Therefore, surgical procedures follow the principles of myth telling. The first myths developed by man concentrated about the translation of the skies. Zodiac signs and cosmic phenomena related to precession of the earth axis were integrated into reports about life and after life. Thus important knowledge has been transferred over many generations and thousands of years. The same happens in modern surgery. In contrast to multi semiotic languages, as applied for classical myth telling, we developed, we invented the academical, scientific language. The Zodiacs and the skies have been translated into the PUB MED platform of our google based internet and collects knowledge, experience and understanding in the form of peer reviewed publications. However, the immense magnitude of large scale novelties and the fast track appearances of these novelties foster a superficial approach. We simply do not have enough space time to get all the informations provided, and it is very difficult to select valuable from less valuable information, without going through all the data. As a consequence, we feel somehow out 
of power and lost within this enormous cosmos of information. Therefore, it may be helpful to invest some space time to analyse the basic mechanisms of disease, as managed by modern, multi-, oligo- and interdisciplinary surgery. Let us try a different approach. We simply ask disease, how to deal with it. Thus: let us open the scene for the disease. The stage is your's "disease".

Welcome dear readers, my name is disease. I am a condition which impairs the life quality, wellbeing and productivity of those, who are allowed to borrow me from the universe. I come and go and I may also stay for longer, I may manifest as a benign or malignant condition. I am different from trauma, although the treatment of mine usually also involves to get rid of the consequences of speed and power related space-time curving within cavities, holes, transitions, doors, ports, excavations, narrowing, dilatations, distentions, blebs, vacuoles, hernias, sacs, balloons, rings, webs and diverticula, nodes, cysts, extractions and strictures. I develop as the consequence of a concentrated sugar induced neuro-humoral response involving many different cell types: epithelia (skin, gut), immune cells, nerve cells and the friends of the connective tissue population. Most importantly I have to admit, that basically there only exist two types of embryologically formatted and regulated types of tissues. One type includes all the connective tissue cells, those ones, who form scars and adhesions, which you, dear surgeon, do not like very much. Then you need strong connective tissues for placing your sutures. Furthermore, those connective tissue cells may help the surgeon to assess, discriminate the tissue layers and thus helps you to perform blood-less surgery. Why? Those connective tissue cells are "intelligent" and mark the bloodless embryological tissue layers, as developed during the genesis of the human animal body. And then there are these other types of cells, which all belong to the nerve cell type. At first glance it seems hard to understand, that epithelial cells, nerve cells, derma cells, brain cells and blood cells are the same type of cell. As a matter of fact, all those cells biochemically act and operate as nerve cells. They are polarised and serve for directed signal transduction. And here the foods and beverages containing concentrated sugar come into play. In the presence of a distinct genetic formatting, concentrated sugar may foster a heuro-humoral response involving all the above cell types. As a consequence, the neuro-humoral cocktail (hormones) activates receptor mediated responses in a given tissue. Based on the genetic formatting, the manifestation of the response may present as hypertension (the cocktail contracts the vascular muscle cells), high cholesterol (sugar impairs the transport of cholesterol into the cell, as a consequence cholesterol values increase in the blood stream); leaky gut syndrome (IBD, UC, CD), leaky lung syndrome (asthma), leaky thyroid syndrome (Hashimoto),- - the sugar induced cocktail always opens the inter-cellular tight junctions-, leaky skin syndrome (Lupus, Skleroderma), leaky joint syndrome (arthritis, rheumatic diseases), and many more (migraine, stroke, obesity, diabetes, cancer etc.). Here, I, the disease, may manifest in many different ways, and this seems to represent and mirror different diseases. But in fact, I only can do one thing: either I tolerate the presence of concentrated sugar, or not. If, due to the genetic formatting, I do not tolerate the concentrated sugar, I will get activated and develop myself in the form of different manifestations. Those are the different clothes (you may say: diseases) I am allowed to wear, but there only exists one common cause: all clothes are woven from the intolerance against concentrated sugar. And here I am (being !) to tell you: if you want to get rid of me, you have to get rid of concentrated sugar containing food and beverages. Otherwise you will continue to support the interests of the sugar industry and the medical industry. You will continue to exists (being!) as a slave of all these despotisms. And I, the disease, have to admit: even your way of living and social organisation, the fact that there exist political systems, companies and value systems (ethics, morals!) is solely related to the control of humans by the sugar industry. As thus you may select: do want to be a slave or open your mind for some level of freedom? The only thing you need for that is discipline. If you wish to learn about the definition of concentrated sugar, if you want to learn, what concentrated sugar is, you may await the upcoming issues of European Surgery, I will not let you down.

Taken together, I am happy that I was allowed to talk to you, and thus I return to where I have come from, to the roots of your eyes. Stay tuned, enjoy living and foster open minded reasoning,

\section{Martin Riegler}

Acknowledgements The author thanks those short moments of atmosphere, which allow to borrow and collect the full beauty of the universe. Full stop. Reggae.

Conflict of interest M. Riegler declares that he has no competing interests.

Publisher's Note Springer Nature remains neutral with regard to jurisdictional claims in published maps and institutional affiliations. 